\title{
Ethyl pyruvate is a novel anti-inflammatory agent to treat multiple inflammatory organ injuries
}

Runkuan Yang ${ }^{1,2,3^{*}} \mathbb{D}$, Shengtao Zhu $^{4}$ and Tor Inge Tonnessen ${ }^{3,5}$

\begin{abstract}
Ethyl pyruvate (EP) is a simple derivative of pyruvic acid, which is an important endogenous metabolite that can scavenge reactive oxygen species (ROS). Treatment with EP is able to ameliorate systemic inflammation and multiple organ dysfunctions in multiple animal models, such as acute pancreatitis, alcoholic liver injury, acute respiratory distress syndrome (ARDS), acute viral myocarditis, acute kidney injury and sepsis. Recent studies have demonstrated that prolonged treatment with EP can ameliorate experimental ulcerative colitis and slow multiple tumor growth. It has become evident that EP has pharmacological anti-inflammatory effect to inhibit multiple early inflammatory cytokines and the late inflammatory cytokine HMGB1 release, and the anti-tumor activity is likely associated with its anti-inflammatory effect. EP has been tested in human volunteers and in a clinical trial of patients undergoing cardiac surgery in USA and shown to be safe at clinical relevant doses, even though EP fails to improve outcome of the heart surgery, EP is still a promising agent to treat patients with multiple inflammatory organ injuries and the other clinical trials are on the way. This review focuses on how EP is able to ameliorate multiple organ injuries and summarize recently published EP investigations.
\end{abstract}

Keywords: Ethyl pyruvate, Inflammation, Reactive oxygen species, HMGB1

\section{Background}

Pyruvate is the final product of glycolysis and the starting substrate for the tricarboxylic acid (TCA) cycle, and this important metabolic intermediate is also an effective scavenger of hydrogen peroxide and other $\operatorname{ROS}[1,2]$. Pharmacological administration of pyruvate is able to improve organ function in animal models of oxidantmediated cellular injury [1, 2]; however, pyruvate is unstable in aqueous solutions and this certainly limits its therapeutic potential. EP, a simple derivative of pyruvic acid, is also an ROS scavenger, but exerts pharmacological effects, such as the anti-inflammatory effects, which are quite distinct from those exerted by pyruvate anion $[1,2]$. Treatment with EP has been shown to improve survival and/or ameliorate multiple organ dysfunctions in a wide variety of preclinical models of critical illnesses [1, 2]. Up

\footnotetext{
* Correspondence: runkuanyang@gmail.com

'Department of Intensive Care Medicine, Tampere University Hospital,

University of Tampere, 10 Bio katu, Tampere 33014, Finland

${ }^{2}$ Department of Critical Care Medicine, University of Pittsburgh Medical

School, 3550 Terrace Street, Pittsburgh, PA 15261, USA

Full list of author information is available at the end of the article
}

to date, about 340 EP related papers have been published; about 100 new papers published after 2010 have not been summarized and reviewed. This review focuses on how EP is able to ameliorate inflammatory injures of multiple vital organs and summarizes new findings from recently published EP investigations.

\section{EP ameliorates severe acute pancreatitis (SAP) and attenuates SAP related distant organ injury} Acute pancreatitis (AP) is a relatively common disease, its severe form is potentially fatal and SAP is associated with high mortality, ranging from $15-40 \%$ [3-8]. The inflammatory cytokines play a crucial role in the pathogenesis of SAP [3, 8, 9]; furthermore, the damaged pancreatic acinar cells and the activated inflammatory cells produce a large amount of oxygen radicals in AP, and these ROS molecules can damage the lipid membranes of pancreatic acinar cells, they can also injure the capillary endothelium in the circulation to accelerate the progress of SAP [7]. Currently, therapeutic efforts are 
limited to supportive measures, because no effective specific treatment exists.

\section{The effect of EP on acute pancreatitis}

EP has been repeatedly reported to ameliorate SAP in different animal models $[4,6,10,11]$. EP treatment [EP source in this review was all from Sigma-Aldrich unless otherwise noted. EP dissolved in commercially available Ringer's lactate solution (RLS). Commercially available RLS was used as the control solution. EP (40 mg/ $\mathrm{kg}$ ) was intraperitoneally injected every $6 \mathrm{~h}$ for $48 \mathrm{~h}$ )] significantly ameliorates pancreatic injury and necrosis $[4,6]$; EP therapy also markedly reduces pancreatic expression of TNF- $\alpha$, IL-6, HMGB1 and NF-kB DNA binding $[4,6]$; treatment with EP reduces the number of inflammatory cell infiltration and decreases the pancreatic level of lipid peroxidation, which is a parameter of ROS [4]. Because early inflammatory cytokines (such as TNF- $\alpha$ and IL-6), late inflammatory mediator HMGB1 and ROS play a significant role in the pathogenesis of SAP $[4,6,10,11]$, and EP can reduce the levels of these inflammatory cytokines and scavenge ROS. Therefore, EP may attenuate pancreatic injury during SAP.

\section{The effect of EP on severe acute pancreatitis related multiple organ injuries}

About $20-30 \%$ of all acute pancreatitis patients develop SAP in clinical practice, and the mortality rate in SAP is $20-30 \%$ [3]. SAP starts as a local inflammation of pancreatic tissue that induces the development of multiple extrapancreatic organs dysfunction $[6,8]$. During SAP, the concentrations of both early (TNF- $\alpha$, IL-6) and late inflammatory cytokines are significantly increased [6,10-13], these cytokines play a significant role in the pathogenesis of SAP $[6,12]$. The late inflammatory cytokine HMGB1 is particularly important because extracellular HMGB1 can aggravate the pancreatic inflammatory process [14] and HMGB1 can also contribute to multiple distant organ injuries in the following experimental models as well: HMGB1 contributes to liver injury in ischemia-reperfusion [15]. Exogenous HMGB1 injection is able to induce liver injury in normal mice [16]. HMGB1 impairs hepatocyte regeneration during acetaminophen hepatotoxicity and blockade of HMGB1 improves hepatocyte regeneration in acetaminophen overdose-induced fatal liver injury [17]. Anti-HMGB1 treatment protects against APAP hepatotoxicity in rats [18]. HMGB1 also contributes to renal ischemia reperfusion injury [19], sepsis-induced kidney injury [20] and severe acute pancreatitis related kidney injury [21]. HMGB1 is also found to significantly contribute to hemorrhagic shock related acute lung injury (ALI) [22]; hypoxia-induced ALI [23] and severe acute pancreatitis related ALI [24]. HMGB1 is also an important factor that not only significantly contributes to gut mucosal injury [16], but also mediates gut bacterial translocation (BT) [25], and blockade of HMGB1 can even prevent gut BT [25]. Gut mucosal injury and intestinal BT in SAP is particularly important because the intestine is the biggest reservoir of bacteria in the body and leakage of bacteria or microbial products, notably LPS, from the lumen of the gut into the systemic circulation, which drives the development of systemic inflammation and multiple organ dysfunction syndrome (MODS) in experimental models [26]. SAP frequently induces gut barrier dysfunction [6, 9, 27, 28]. The small intestine becomes damaged by intestinal ischemia-reperfusion during SAP $[29,30]$, and the failure of gut barrier is associated with BT [29], which is evident in SAP [6, 27, 28, 31]. SAP patients have significantly increased serum LPS [32], 68.8\% of the SAP patients have bacteraemia and these bacteria are highly likely gut-derived opportunistic pathogens [27]. Furthermore, BT and infected pancreatic necrosis in acute necrotizing pancreatitis derive from small bowel rather than from the colon [28]. BT and/or gut derived LPS play a critical role in the development of systemic inflammatory response syndrome (SIRS) and MODS during SAP $[29,33]$, because BT not only contributes to pancreatic infection [28, 33], but also induces/triggers SIRS/sepsis in critical illness [33, 34]. The profound SIRS/sepsis can lead to MODS and mortality in SAP [9, 29, 31, 33], this is one of the underlying mechanisms that AP frequently affects extrapancreatic organs $[6,25]$, and the incidence of MODS in SAP is not available but certainly higher than the $20-30 \%$ of mortality rate in SAP [3]. Systemic inflammation with multi-organ dysfunction is the cause of death in a murine ligation-induced SAP, and SIRS and MODS can lead to the preponderance of mortality (75\%) in this lethal SAP model [9] while bile duct ligation does not have mortality, even though obstructive jaundice is prone to sepsis [9]. Therefore, the gut is thought to act as the starter of SIRS [29] and HMGB1 may be an important factor that links gut barrier dysfunction and MODS during SAP. EP (40 mg/kg was intraperitoneally injected every $6 \mathrm{~h}$ for $48 \mathrm{~h}$ ) can ameliorate SAP related multiple organ injuries $[6,10,11]$ at least partly because EP not only reduces the inflammation in these organs $[6,10,11]$, but also inhibits nearly $90 \%$ of the hepatic tissue HMGB1 to release [12] and other related cells to release HMGB1 [10, 12], thereby decreases the circulating HMGB1 level in SAP $[10,14]$. Thus, HMGB1 is an important factor that not only directly contributes to multiple organ injuries, but also mediates gut BT to trigger/induce systemic inflammation/sepsis, the latter can lead to MODS. Currently, the circulating HMGB1 level is thought to be reliable to predict the severity of SAP $[10,14]$, this is likely because HMGB1 is linked to multiple organ injuries during SAP $[10,12,14]$, the liver is an important source of 
circulating HMGB1 [12], and the circulating HMGB1 level could reflect the severity of liver injury, which is one of the important parameters for diagnosing SAP $[6,12]$. SAP associated BT was reduced by $90 \%$ following EP treatment [6] breaking the link between BT and MODS. Therefore, EP could be a better treatment option against SAP related multiple organ injuries in experimental models $[6,10,11]$.

\section{The effect of EP on liver injuries}

The liver is the largest organ in the body, hepatocytes account for $70-80 \%$ of the hepatic cytoplasmic mass and non-parenchymal cells make up $20-30 \%$ of the hepatic cytoplasmic mass [35]. Kupffer cells (KCs) are the most abundant mononuclear phagocytes in the body and a predominant source of inflammatory cytokines released into the systemic circulation [8]. The amount of cytokines released from the liver represents about $50 \%$ of the total cytokine content in the body [36], suggesting that the liver is the major contributor of the circulating cytokines.

\section{EP ameliorates experimental alcoholic liver injury}

Alcoholic hepatitis is associated with considerable morbidity; $46 \%$ of patients with the severe alcoholic hepatitis die within 30 days of the onset [37]. General measures for treatment include abstinence from alcohol and supportive care. Alcoholic hepatitis is reversible if the patient stops drinking, it usually takes several months to resolve, however, abstinence from alcohol is difficult, and the treatment is still challenging. In an experimental murine model, alcohol induces fatty change and piecemeal necrosis; alcohol administration also induces significantly increased hepatic lipid peroxidation, NF-kB activation, TNF- $\alpha$ mRNA expression; furthermore, alcohol administration induces a large amount of gut BT, which can serve as the "second hit" to contribute to the alcoholic liver injury. All of these alcohol-induced effects are ameliorated by treatment with EP $(40 \mathrm{mg} / \mathrm{kg}$ was intraperitoneally injected every $6 \mathrm{~h}$ for $48 \mathrm{~h}$ ) instead of Ringers lactate solution, suggesting that EP ameliorates hepatic inflammatory response and hepatic lipid peroxidation, and resultantly decreases hepatocellular injury duo to acute alcoholic intoxication [37].

\section{EP ameliorates experimental obstructive jaundice induced} liver injury

Obstructive jaundice and cholangitis are common diseases that are prone to sepsis that can lead to mortality [38]. In an experimental murine model of common bile duct ligation model [38], obstructive jaundice induces evident hepatocellular necrosis and significantly increased circulating ALT and total bilirubin levels. Obstructive jaundice also induces increased hepatic lipid peroxidation and increased hepatic expression of transcripts for TNF- $\alpha$, IL- 6 , and iNOS. Furthermore, bile duct ligation also induces a large amount of gut BT, which can serve as the "second hit" to contribute to the liver injury. All of these changes can be significantly attenuated by delayed treatment with EP $(40 \mathrm{mg} / \mathrm{kg}$ was intraperitoneally injected every $8 \mathrm{~h}$ for $72 \mathrm{~h}$ ) instead of RLS, suggesting that EP ameliorates hepatic inflammation, lipid peroxidation and necrosis in obstructive jaundice [38]. In addition, EP treatment increases NF-kB DNA binding, which often modulates inflammation when hepatic necrosis is not evident [37] but modulates regeneration when hepatic necrosis is evident [38], this concept has been proved in acetaminophen hepatotoxicity in which massive hepatocyte necrosis is a predominant feature $[39,40]$. Therefore, it is likely that EP enhances NF-kB DNA binding to improve hepatocyte regeneration in obstructive jaundice.

\section{EP ameliorates acute liver injury secondary to severe acute pancreatitis}

SAP frequently affects the liver and the inflamed liver play a significant role in the pathogenesis of SAP $[6,12,13]$. In a lethal experimental SAP murine model, SAP induces significantly increased hepatic lipid peroxidation, NF-kB activation, hepatic expression of transcripts for TNF- $\alpha$, IL-6, iNOS and COX-2 [12]. SAP also induces focal hepatocyte necrosis and a large number of inflammatory cell infiltration $[6,12,13]$, all of these changes can be significantly decreased by delayed treatment with EP instead of Ringers lactate solution [12]. In particular, SAP can induce the loss of nearly $85 \%$ of hepatic tissue HMGB1 tested by western blot using whole hepatic tissue, and this effect can be reversed by EP treatment $(40 \mathrm{mg} / \mathrm{kg}$ intraperitoneally injected every $6 \mathrm{~h}$ for $48 \mathrm{~h}$ ) [12], suggesting that the liver is an important resource of the circulating HMGB1, and EP is a potent HMGB1 inhibitor [12]. In another SAP rat model, SAP induces significantly increased hepatic lipid peroxidation, hepatic NF-kB DNA binding and hepatic expression of transcripts for TNF- $\alpha$, IL-1 and HMGB1 [13], all of these changes can be significantly reduced by EP treatment $(40 \mathrm{mg} / \mathrm{kg}$ intraperitoneally injected every $6 \mathrm{~h}$ for $48 \mathrm{~h}$ ) [13].

\section{The effect of EP on fatty liver}

Fatty liver is common world widely, and its treatment is problematic. In a high-fat induced rat model, the fatty liver induces increased serum ALT and increased hepatic TNF- $\alpha$ level; these changes can be significantly decreased by EP intake (supplemented in 0.3\% drinking water for 6 weeks) but EP does not affect the development of a fatty liver [41], suggesting that EP can protect against inflammation induced liver cell damage but EP cannot prevent the development of fatty liver in animal experiment. 
The effect of EP on hepatic ischemia-reperfusion injury Hepatic ischemia-reperfusion (I/R) is a pivotal clinical problem occurring in many clinical conditions such as transplantation, trauma and hemorrhagic shock [42]. Hepatic I/R induces significantly increased hepatic expression of TNF- $\alpha$, IL-6, HMGB1 and NF-kB activation, and hepatic I/R also induces markedly increased hepatic expression of $\mathrm{Bcl}-2$, Bax, Beclin-1 and LC3, which play an important role in the regulation of intrinsic pathway of apoptosis and autophagy, all of these changes are significantly reduced by EP treatment $(1 \mathrm{~h}$ before the ischemia procedure, a single dose of EP was intraperitoneally injected to animals in the $20 \mathrm{mg} / \mathrm{kg}$ group, the $40 \mathrm{mg} / \mathrm{kg}$ group and the $80 \mathrm{mg} / \mathrm{kg}$ group, liver tissue samples were obtained $4 \mathrm{~h}, 6 \mathrm{~h}$ and $16 \mathrm{~h}$ after I/R), suggesting that EP ameliorates hepatic $I / R$ injury via its antiinflammatory and its anti-apoptosis effect.

\section{The effect of EP on acute fatal liver injury}

Drug-induced acute fatal liver injury is the leading cause of acute liver failure (ALF) in the developed countries [43-46], and ALF has a high mortality and the treatment is still quite challenging [43].

Concanavalin A induces autoimmune hepatitis with significantly increased hepatic expression of TNF- $\alpha$, IL- 6 , IL-1, HMGB1 and NF-kB activation, EP treatment (1 h before the Con A injection, a single dose of EP was intraperitoneally injected to the animals in the $40 \mathrm{mg} / \mathrm{kg}$ EP group and the $80 \mathrm{mg} / \mathrm{kg}$ EP group; liver tissue samples were obtained $3 \mathrm{~h}$, $6 \mathrm{~h}$ and $24 \mathrm{~h}$ after Con A injection) reduces all of these changes and resultantly ameliorates Concanavalin induced autoimmune hepatitis [44], which can be fatal.

D-galactosamine induces acute fatal liver injury with significantly increased serum TNF- $\alpha$, HMGB1, IFNgamma and endotoxin, all of these changes can be significantly decreased by EP treatment (A single dose of $40 \mathrm{mg} / \mathrm{kg}$ EP was intraperitoneally injected $2 \mathrm{~h}$ after ALF induction, samples were taken $22 \mathrm{~h}$ after EP injection), therefore, EP can ameliorate acute fatal liver injury induced by $\mathrm{D}$-galactosammine [45].

Acute-on-Chronic liver failure (ACLF) rats have significantly increased serum endotoxin, TNF- $\alpha$, HMGB1, IFN-gamma and IL-18, EP administration $(40 \mathrm{mg} / \mathrm{kg}$ was intraperitoneally injected at $3 \mathrm{~h}, 6 \mathrm{~h}, 12 \mathrm{~h}, 24 \mathrm{~h}$ after the induction of ACLF, and samples were taken $48 \mathrm{~h}$ after the induction of ACLF) decreases all of these changes to protect against ACLF in rats [46].

Acetaminophen is the leading cause of drug induced ALF, and EP treatment $(40 \mathrm{mg} / \mathrm{kg}$ was intraperitoneally injected every $8 \mathrm{~h}$ for $24 \mathrm{~h}$ ) can reduce liver injury at early phase by its potent anti-inflammatory effect [43].

\section{The effect of EP on diabetes induced liver injury}

Diabetes can lead to an increased oxidative stress that significantly contributes to diabetes-induced liver injury
[47]. Diabetes induces significantly increased total antioxidant status and hepatic peroxidation. EP therapy $(50 \mathrm{mg} / \mathrm{kg}$ was intraperitoneally injected twice a day for 14 days) (instead of Ringer solution) significantly decreases all of these changes and resultantly ameliorates diabetes-induced liver injury in a streptozocin induced diabetic rat model [47].

\section{The effect of EP on acute lung injuries}

\section{EP on SAP related acute lung injury}

Acute lung injury (ALI), also addressed as mild acute respiratory distress syndrome (MARDS), is a significant health problem associated with high mortalities $[8,48]$; MARDS is also a severe complication and a major feature of MODS to SAP [8]. In patients with AP, up to $20 \%$ of all deaths occur prior to admission to hospitals, and MARDS is the predominant cause of death in these cases [48]. In SAP, the MARDS is the main contributing factor to early deaths, i.e. within the first week after admission [49]. The inflammatory mediators and the profound SIRS are thought to play a key role in the development of MARDS $[3,50,51]$ because the significantly increased serum inflammatory mediators activate alveolar macrophages to release chemotactic mediators that play an important role in recruiting neutrophils, which work together with the elevated circulating pro-inflammatory mediators to severely damage alveolar epithelium and microvascular endothelium, and resultantly causes the increased permeability of the alveolar-capillary barrier and pulmonary edema. This theory is supported by the following evidence in which the alveolar-capillary barrier is severely injured and the pulmonary permeability is significantly increased in an experimental acute necrotizing pancreatitis [6]. The antiinflammatory agent EP $(40 \mathrm{mg} / \mathrm{kg}$ intraperitoneally injected every $6 \mathrm{~h}$ for $48 \mathrm{~h}$ ) markedly decreases the lung permeability and alleviates pulmonary edema at least partly by reducing pulmonary inflammation and neutrophils infiltration in a couple of experimental SAP models with acute lung injury $[6,10,52,53]$. Increased local and systemic levels of IL-6 are associated with inflammatory process, including neutrophil infiltration of the alveolar space, resulting in lung injury [54]. EP treatment reduces the IL-6-induced release of IL-8 and decreases IL-6induced neutrophil adhesion to the lung epithelial cells [54], and this anti-inflammatory effect is via Akt and NFkB p65 pathway [55]. Therefore, EP reduces secretory and adhesive potential of lung epithelial cells under inflammatory conditions $[54,55]$.

\section{The effect of EP on endotoxin-induced acute lung injury} LPS intravenous injection induces significantly increased plasma TNF- $\alpha$, IL-6; LPS administration also induces significantly increased expression of $\mathrm{HO}-1$ and iNOS in lung tissue. In addition, LPS also induces lung edema 
and infiltration of neutrophils, all of these changes can be reduced by EP treatment (intravenously infused for $4 \mathrm{~h}$ into the animals in the following 3 different EP concentration groups: 20,40 and $60 \mathrm{mg} / \mathrm{kg}$, and lung tissue samples were harvested $6 \mathrm{~h}$ after EP administration) [56]. In a murine model, LPS intratracheal administration significantly increases the release of TNF- $\alpha$, IL-6, IL-1 and HMGB1 into bronchoalveolar lavage, all of these changes can be markedly decreased by EP treatment $(100 \mathrm{mg} / \mathrm{kg}$ was intraperitoneally injected at $0 \mathrm{~h}$, $12 \mathrm{~h}, 24 \mathrm{~h}$ and $48 \mathrm{~h}$ after the induction of ALI), and early administration of EP can improve survival [57].

\section{The effect of EP on hyperoxia-induced acute lung injury} Prolonged exposure to hyperoxia results in ALI, accompanied by significantly increased levels of proinflammatory cytokines and a large number of leukocyte infiltration in the lungs [58]. HMGB1 plays a critical role in mediating hyperoxia induced ALI through the recruitment of leukocytes into the lung [58], a single dose of EP treatment $(40 \mathrm{mg} / \mathrm{kg}$ intraperitoneal injection prior to hyperoxia exposure, and lung tissue samples were taken $24 \mathrm{~h}$ after hyperoxia exposure) attenuates the hyperoxia induced ALI probably by inhibiting HMGB1 secretion from hyperoxic macrophages [58], suggesting that EP may treat oxidative inflammatory lung injury in patients receiving hyperoxia through mechanical ventilation.

\section{The effect of EP on macrophages, systemic inflammation and sepsis}

EP inhibits LPS-stimulated macrophages to release both early and late inflammatory cytokines

In cultured macrophages, LPS stimulates the macrophages to release TNF- $\alpha$, IL- 6 , and HMGB1, and these changes can be effectively prevented by EP treatment (cells were incubated with $25 \mathrm{mM}$ EP for $48 \mathrm{~h}$ ) [59]. LPS stimulates macrophages to release HMGB1 and up-regulates iNOS expression, EP treatment (cells were incubated with $25 \mathrm{mM} \mathrm{EP}$ for $24 \mathrm{~h}$ ) can reverse these effects by inducing heme oxygenase-1 (HO-1) via a 338 MAKP- and NRF2dependent pathway [60]. HMGB1 is a ubiquitous nuclear protein that can be actively secreted by immunocompetent cells, including monocytes, macrophages and neutrophils, and this highly conservative nuclear protein is an important late inflammatory mediator in sepsis [61]. HMGB1 can also be passively released by dying cells or necrotic tissue [25]. HMGB1 plays an important role in modulating inflammatory cascade in activated macrophages: HMGB1 stimulates macrophages to release TNF- $\alpha$ and IL-6, while HMGB1neutralizing antibody can block TNF- $\alpha$ release $[62,63]$ and knocking-out HMGB1 receptor can reverse IL-6 release [63]. In macrophages cultures, LPS stimulates macrophages to release high concentrations of early inflammatory cytokines such as TNF- $\alpha$, IL-6 and IL-1 and the late mediator HMGB1 [61-63], and EP treatment reduces these changes by specifically inhibiting the activation of p38 mitogen activated protein kinase and NF-kB, two signalling pathways that are critical for cytokines release [61].

\section{EP prevents lethality in mice with sepsis and systemic inflammation}

Sepsis is a serious clinical syndrome, which is mediated by an early (such as TNF- $\alpha$ and IL-1) and late (such as HMGB1) pro-inflammatory cytokine response to infection [61]. Delayed treatment with EP $(40 \mathrm{mg} / \mathrm{kg}$ intraperitoneally injected $24 \mathrm{~h}, 30 \mathrm{~h}, 48 \mathrm{~h}$, and $54 \mathrm{~h}$ after cecal puncture, the experiment finished $120 \mathrm{~h}$ after cecal puncture) significantly increases survival and markedly reduces circulating levels of HMGB1 in mice with sepsis [61]. EP increases survival and decreases serum HMGB1 by up-regulation of HO-1 level in septic animals [60]. In an established septic animal model, sepsis induces significantly increased plasma TNF- $\alpha$, IL- 6 and IL-1; sepsis also increases hepatic lactate, lactate/pyruvate levels and down-regulates hepatic ATP and energy charge levels; all of these effects can be reversed in the septic mice treated with a single dose of EP $(40 \mathrm{mg} / \mathrm{kg}$ intraperitoneal injection, and the liver samples were taken $6 \mathrm{~h}$ after EP injection), suggesting that EP protects against sepsis by regulating energy metabolism and inhibiting systemic inflammation [64]. In addition, EP improves sepsis outcome by reducing mitochondrial swelling and dysfunction in experimental sepsis [65]. Septic patients have significantly increased serum HMGB1 levels, which can induce endothelial cell hyperpermeability via BAX and BCL-2 regulated apoptosis, EP can reverse these detrimental effects to prevent endothelial cell injury in experimental sepsis [66]. Furthermore, EP can effectively reduce vascular endothelial inflammation and this effect at least partly depends on the attenuation of endoplasmic reticulum stress [67].

\section{The effect of EP on acute kidney injuries}

Acute kidney injury (AKI) is a common serious complication of SAP and sepsis. Endotoxin and ROS play an important role in the pathogenesis of AKI and SAP.

\section{The effect of EP on sepsis-induced acute renal failure}

Sepsis is a common cause of acute renal failure (ARF), and the incidence of sepsis increases markedly after age of 50 [68]. Sepsis induces significantly increased plasma TNF- $\alpha$, creatinine and causes tubular damage and multiple organ injury, sepsis also induces increased mRNA for TNF- $\alpha$, tissue factor, PAI-1, and urokinase-like plasminogen activator; all of these changes can be significantly decreased by EP treatment (a single dose of $40 \mathrm{mg} / \mathrm{kg}$ was intraperitoneally injected $12 \mathrm{~h}$ after cecal 
puncture and experiment finished $24 \mathrm{~h}$ after cecal puncture), therefore, EP attenuates sepsis-induced ARF in an animal model [68].

\section{The effect of EP on diabetic nephropathy}

Diabetic nephropathy is a common complication [69]. Diabetic rats have increased laminin, type IV collagen and fibronectin deposition in the glomeruli and these animals also have albuminuria and increased NADPHdependent ROS generation; all of these changes can be significantly decreased by EP treatment $(40 \mathrm{mg} / \mathrm{kg}$ intraperitoneally injected every other day for 12 weeks) [69], suggesting that EP might be a novel therapy to treat diabetic nephropathy.

\section{The effect of EP on cisplatin-induced nephrotoxicity}

Cisplatin-induced nephrotoxicity is common in clinical practice. Cisplatin induces significantly increased perfusion pressure, serum urea, creatinine, total oxidant status and tissue lipid peroxidation, all of these changes can be significantly decreased by EP therapy $(50 \mathrm{mg} / \mathrm{kg}$ was intraperitoneally injected once a day for 5 days) [70], suggesting that EP has a protective effect against cisplatin nephrotoxicity.

\section{The effect of EP on heart injury}

\section{EP attenuates acute viral myocarditis}

Inflammation plays important roles in the pathogenesis of coxsackievirus B3 (CVB3)-induced acute viral myocarditis (AVMC) [71]. CVB3 virus induces increased levels of HMGB1, TNF- $\alpha$, IL-1, IL-17 in the heart and serum of the AVMC mice, and all of these changes can be significantly decreased by EP treatment $(40 \mathrm{mg} / \mathrm{kg} /$ day and $80 \mathrm{mg} / \mathrm{kg} /$ day intraperitoneally injected on day 5 , day 6 and day 7 post infection), and this protective effect is associated with inhibition of HMGB1/RAGE/NF$\mathrm{kB}$ pathway [71].

\section{EP protects against myocardial ischemia/reperfusion}

HMGB1 is a late inflammatory cytokine that triggers and amplifies the inflammation cascade following ischemia/reperfusion (I/R), and EP can inhibit HMGB1 release in $I / R$ models [72]. I/R procedure induces increased levels of HMGB1, TNF- $\alpha$, IL- 6 , these changes can be significantly reduced by EP treatment (a single dose of EP with $40 \mathrm{mg} / \mathrm{kg}$ concentration was intravenously injected prior to the $48 \mathrm{~h}$ reperfusion) instead of PBS, the accumulation of HMGB1 is deleterious to the heart following myocardial I/R [72]. In another rat cardiac I/R model, EP treatment significantly preserves cardiac function, enhances tissue ATP levels, attenuates myocardial oxidative injury and reduces apoptosis following myocardial ischemia [73]. In another regional heart I/R rat model, EP therapy (a single dose of $40 \mathrm{mg} / \mathrm{kg}$ was intraperitoneally injected $1 \mathrm{~h}$ prior to the $24.5 \mathrm{~h} \mathrm{I} / \mathrm{R}$ procedure) inhibits I/R-induced NF-kB translocation and neutrophil activation in myocardium, EP also decreases the serum levels of inflammatory cytokines, and resultantly EP improves cardiac function and reduces infarct size after regional $I / R$ injury [74]. In another prolonged rat myocardial ischemia model, EP therapy enhances myocardial ATP levels, attenuates myocardial oxidative injury, and resultantly decreases infarct size and preserves cardiac function [75].

\section{The effect of EP on acute brain injury}

EP attenuates traumatic brain injury

In a rat model of unilateral cortical contusion injury (CCI), EP treatment $(40 \mathrm{mg} / \mathrm{kg}$ was intraperitoneally injected $1 \mathrm{~h}, 12 \mathrm{~h}$ and $24 \mathrm{~h}$ after brain injury, brain samples were harvested $72 \mathrm{~h}$ after brain injury) significantly decreases the number of dead/dying cells in the ipsilateral hippocampus and improves recovery of beamwalking, neurological scores after injury, suggesting that EP treatment after CCI is neuroprotective and improves neurobehavioral recovery [76]. Traumatic brain injury (TBI) can cause brain cell death/dying, and the/dead/ dying cells can release nuclear protein HMGB1 that can activate inflammatory pathways, therefore, the HMGB1 inhibitor EP $(75 \mathrm{mg} / \mathrm{kg}$ was intraperitoneally injected at $5 \mathrm{~min}, 1 \mathrm{~h}, 6 \mathrm{~h}$ after brain injury, and brain samples were harvested $24 \mathrm{~h}$ after brain injury) significantly decreases the expressions of HMGB1, TLR4, NF-kB DNA binding and inflammatory mediators, such as, TNF- $\alpha$, IL- 1 and IL-6. EP treatment also ameliorates beam walking performance, brain edema and cortical apoptotic cell death, suggesting that the protective effects of EP maybe mediated by the reduction of HMGB1/TLR4/NF-kB-mediated inflammatory response in the injured rat brain [77]. Many TBI survivors sustain neurological disability and cognitive impairment due to the lack of defined therapy to reduce TBI-induced long-term brain damage, EP (40 mg/kg was intraperitoneally injected at $15 \mathrm{~min}, 12 \mathrm{~h}$, $24 \mathrm{~h}, 36 \mathrm{~h}, 48 \mathrm{~h}, 60 \mathrm{~h}$ after brain injury, and brain samples were taken 28 days after brain injury) confers longterm neuroprotection against TBI, possibly via breaking the vicious cycle among matrix metalloproteinase-9mediated blood-brain barrier disruption, neuroinflammation and long-lasting brain damage [78]. Experimental TBI is known to produce an acute increase in cerebral glucose utilization, followed rapidly by a generalized cerebral metabolic depression. Early administration of EP $(40 \mathrm{mg} / \mathrm{kg}$ was intraperitoneally injected at $0 \mathrm{~h}, 1 \mathrm{~h}, 3 \mathrm{~h}, 6 \mathrm{~h}$ after brain injury, and brain samples were harvested 24 after brain injury) enhances cerebral glucose metabolism and neuronal survival, therefore, EP therapy is able to attenuate cerebral metabolic depression and neuronal loss after traumatic brain injury [79]. 
EP ameliorates acute intracerebral haemorrhage-induced brain injury

Intracerebral haemorrhage $(\mathrm{ICH})$ is a devastating disease with no specific treatment. Increasing evidence indicates that inflammatory response plays an important role in ICH-induced brain damage [80, 81]. In a murine model of $\mathrm{ICH}, \mathrm{EP}$ treatment (3 concentrations of EP at $10 \mathrm{mg} / \mathrm{kg}$, $50 \mathrm{mg} / \mathrm{kg}$ and $100 \mathrm{mg} / \mathrm{kg}$ were intraperitoneally injected to animals in 3 separate groups at $1 \mathrm{~h}, 6 \mathrm{~h}, 12 \mathrm{~h}$ after the induction of $\mathrm{ICH}$, and brain samples were harvested $72 \mathrm{~h}$ after the induction of $\mathrm{ICH}$ ) reduces brain edema and improves neurological function after ICH. EP also protects neurons from haemoglobin-induced cell death in vitro and neuronal cell degeneration in $\mathrm{ICH}$ mice. EP exerts anti-inflammatory effects via inhibiting microglia activation, NF-kB activation and decreasing TNF- $\alpha$, IL-1 production. These results indicate that EP protects $\mathrm{ICH}$ induced brain damage via anti-cell death and antiinflammatory actions [80]. In another rat $\mathrm{ICH}$ model, EP treatment $(40 \mathrm{mg} / \mathrm{kg}$ was intraperitoneally injected at $1 \mathrm{~h}$, $6 \mathrm{~h}$ and $12 \mathrm{~h}$ after the induction of $\mathrm{ICH}$, and brain samples were harvested $72 \mathrm{~h}$ after the induction of $\mathrm{ICH}$ ) significantly reduces inflammatory cell infiltration and expression of IL-1, matrix metalloproteinase-9 in the perihematoma after $\mathrm{ICH}$. EP therapy also shows less brain edema, less haemorrhage and greater neurobehavioral function. The results suggest that EP ameliorates inflammatory damage after ICH via HMGB1-RAGE signalling pathway [81].

\section{EP alleviates early brain injury induced by subarachnoid hemorrhage}

Subarachnoid hemorrhage $(\mathrm{SAH})$ is also a devastating disease with no specific treatment [82]. In a rat model of $\mathrm{SAH}, \mathrm{EP}$ treatment (A single dose of EP at $100 \mathrm{mg} / \mathrm{kg}$ concentration was intraperitoneally injected $1 \mathrm{~h}$ after the induction of $\mathrm{SAH}$, and brain samples were harvested $24 \mathrm{~h}$ after the induction of SAH) inhibits microglia activation and reduces the expression of inflammatory cytokines TNF- $\alpha$ and IL-1; EP therapy also inhibits apoptosis and prevents the disruption of tight junction proteins to stabilize the BBB [82].

\section{EP decreases the cerebral ischemic injury}

In a rat cerebral ischemia model, EP administration (intraperitoneally injected at the doses of 1, 4, 20 and $40 \mathrm{mg} / \mathrm{kg}$ at $4 \mathrm{~h}$ and $24 \mathrm{~h}$ after the brain ischemia injury, and the size of infarct was assessed after 2 days of reperfusion) significantly reduces infarct volume and also suppresses the infarct volume related motor impairment, neurological deficits, microglial activation and inflammatory cytokine expression. Furthermore, the neuroprotective effect is still evident even when the EP treatment is given as late as $24 \mathrm{~h}$ after the cerebral ischemia induction, suggesting that EP can protect against cerebral ischemia injury with a wide therapeutic window [83].

\section{EP exerts neuroprotective effects against hypoxic- ischemic brain jury}

Neonatal hypoxic-ischemic (HI) brain injury causes severe brain damage in newborns. Following HI injury, rapidly accumulating oxidants injure neurons and interrupt ongoing developmental processes [84]. EP therapy (a single dose of EP at $25 \mathrm{mg} / \mathrm{kg}$ was intraperitoneally injected $30 \mathrm{~min}$ after HI brain injury, and brain samples were harvested at 3 h, 6 h, 12 h, 24 h,48 h,72 h, 7 days and 4 weeks after HI brain injury) and the insulin-like growth factor-1 (IGF-1) treatment protect the neonatal rats brain against $\mathrm{HI}$ injury and improve neurological performance and these effects are additive [84].

\section{The effect of EP on inflammatory bowel disease}

Inflammatory bowel disease is characterized by overproduction of inflammatory mediators and reactive oxygen that induce intestinal damage and chronic inflammation. Inflammatory bowel disease is common but the treatment is still challenging $[85,86]$. In a rat TNBS-induced colitis model, EP treatment $(20 \mathrm{mg} / \mathrm{kg}, 40 \mathrm{mg} / \mathrm{kg}$ and $100 \mathrm{mg} / \mathrm{kg}$ were orally administered to 3 separate groups once a day for 7 days) significantly recovers the mucosal cytoarchitecture by reducing neutrophil infiltration and decreasing the levels of multiple inflammatory mediators (IL-1, IL-17, IL-6, IL-23, iNOS) [86]. EP therapy (40 mg/ $\mathrm{kg}$ was intraperitoneally injected once a day for 7 days) also ameliorates experimental colitis in mice by inhibiting the HMGB1-Th17 and Th1/Tcl responses [85].

\section{The effect of EP on tumour}

As inflammation is linked to cancer growth, the antiinflammatory agent EP is expected to have anti-tumor activity, and EP administration $(40 \mathrm{mg} / \mathrm{kg}$ and $80 \mathrm{mg} / \mathrm{kg}$ intraperitoneally injected once a day for 9 days) significantly inhibits hepatic tumor growth [87]. The low-cost EP (40 mg/kg intraperitoneally injected twice a day for 3 weeks) elicits a potent immune-based antitumor response through inhibition of indoleamine 2, 3-dioxygenase (IDO), a key tolerogenic enzyme for many human tumors [88]. EP treatment $(40 \mathrm{mg} / \mathrm{kg}$ intraperitoneally injected once a day for 2 weeks) inhibits tumor angiogenesis by inhibition of the NF-kB signalling pathway [89]. HMGB1 and RAGE are significantly expressed in gastric adenocarcinoma, and EP treatment $(40 \mathrm{mg} / \mathrm{kg}$ and $80 \mathrm{mg} / \mathrm{kg}$ intraperitoneally injected once a day for 2 weeks) inhibits gastric cancer growth via regulation of the HMGB1-RAGE and Akt pathways [90]. EP administration (cultured cancer cells were treated with EP at $10 \mathrm{mM}$ and $20 \mathrm{mM}$ for up to $120 \mathrm{~h}$ ) also inhibits growth and invasion of gallbladder cancer cells via down-regulation of the HMGB1-RAGE axis [91]. 
Hepatocellular carcinoma (HCC) develops in response to chronic hepatic injury. Although p53 is usually regarded as a tumor suppressor, its constant activation can promote pro-tumorigenic inflammation, at least in part, via inducing HMGB1 release. EP administration ( $40 \mathrm{mg} / \mathrm{kg}$ was intraperitoneally injected once every other day for 7 weeks) prevents tumorigenesis in rat livers by restoring $\mathrm{p} 53$, and EP treatment does not affect p53-mediated hepatic apoptosis [92]. Furthermore, EP treatment (Cultured cancer cells were treated with $10 \mathrm{mM}, 20 \mathrm{mM}$ EP up to $72 \mathrm{~h}$ ) induces apoptosis and cell-cycle arrest in G phase in hepatocellular carcinoma cells [93]. In addition, EP treatment (Cultured cancer cells were treated with $10 \mathrm{mM}, 20 \mathrm{mM}, 40 \mathrm{mM}$ EP up to $120 \mathrm{~h}$ ) defangs some malignancy-associated properties of prostate cancer cells including proliferation, invasion and anchorage-independent growth [94]. Taken together, EP may have a potential as a new multi-functional compound for cancer therapy.

\section{Molecular mechanisms responsible for the anti- inflammatory effects of EP}

EP does not inhibit nuclear translocation of NF-kB family members but attenuates NF-kB DNA binding in an experimental colitis model [95], more specifically, EP inhibits NF$\mathrm{kB}$ activation by alkylating a critical cysteine residue $\left(\mathrm{Cys}^{38}\right)$ in the p65 subunit of the NF-kB heterodimer, and alkylation of $\mathrm{Cys}^{38}$ interferes with DNA-binding by the transcription factor $[1,2]$. EP also interacts with NF-kB subunits, Rel A and p50 to inhibit their functions at multiple points, for example, EP is able to inhibit the nuclear association of Rel A after TNF- $\alpha$ treatment [96]. At least some of the antiinflammatory effects EP are related to its ability to scavenge ROS, since EP is an anti-oxidant $[1,2,12]$, and oxidative stress is able to activate NF-kB-dependent gene transcription $[1,2,12]$. EP not only prevents nuclear-to-cytoplasmic translocation of HMGB1 [95], but also inhibits cytoplasmic HMGB1 to be released extracellularly [12]. Moreover, EP inhibits HMGB1 release from primary microglial cells via direct intracellular $\mathrm{Ca}(2+)$ chelation [97], and EP also regulates inflammation and exerts a neuroprotective effect via dual functions, chelating intracellular $\mathrm{Zn}(2+)$ and promoting NAD replenishment [98].

\section{EP administration on translational/clinical practice}

EP therapy has been confirmed to be effective and safe in multiple SAP animal models and multiple liver injury models, it would be reasonable to focus on SAP and alcoholic hepatitis clinical trials next step. Intravenous infusion is used to administer EP (from Critical Therapeutics Inc, Lexington, MA, USA) to healthy volunteers and high-risk patients undergoing coronary artery bypass graft and/or cardiac valvular surgery with cardiopulmonary bypass. EP $(90 \mathrm{mg} / \mathrm{kg})$ was administered intravenously starting after the induction of general anesthesia followed by 5 more doses of $90 \mathrm{mg} / \mathrm{kg}$ administered every $6 \mathrm{~h}$. EP treatment did not reduce major complications within 14 or 28 days of surgery. EP solution has a $\mathrm{pH}$ of less than 7, so EP administration may contribute to acidosis, however, no significant safety concerns were discovered during the clinical trial because the adverse event profile for patients receiving EP $(n=49)$ was similar to that of patients receiving placebo $(n=53)$. EP administration has been proved to be safe in a large number of experimental animals, no severe side effect has been reported.

\section{Conclusions}

$\mathrm{EP}$ is a novel anti-inflammatory agent and ROS scavenger, this safe and low-cost compound is able to treat multiple inflammatory organ injuries and systemic inflammation in experimental animal models. EP also has a potential to inhibit multiple tumor growth, and this anti-tumor activity may be associated with its anti-inflammatory effect.

\section{Abbreviations \\ AKl: Acute kidney injury; ALF: Acute liver failure; ALI: Acute lung injury; APAP: Acetaminophen; ARDS: Acute respiratory distress syndrome; BT: Bacterial translocation; CCl: Cortical contusion injury; DAMP: Damage associated molecular pattern; EP: Ethyl pyruvate; HCC: Hepatocellular carcinoma; HI: Hypoxic-ischemic; HMGB1: High mobility group box 1; ICH: Intracerebral haemorrhage; \\ IDO: Indoleamine 2, 3-dioxygenase; IGF-1: Insulin-like growth factor-1; KCs: Kupffer cells; MAPK: Mitogen activated protein kinase; MODS: Multiple organ dysfunction syndrome; ROS: Reactive oxygen species; SAH: Subarachnoid hemorrhage; \\ SAP: Severe acute pancreatitis; SIRS: Systemic inflammatory response syndrome; \\ TBI: Traumatic brain injury; TCA: The tricarboxylic acid; TLR: Toll like receptor}

\section{Acknowledgements}

Not applicable.

\section{Funding}

This investigation was partly supported by Sigrid Juselius Funding in Finland and South-Eastern Norway Regional Health Authority, Grant number 2013121.

Availability of data and materials

Data sharing not applicable to this article as no datasets were generated or analyzed during the current study.

\section{Author contributions}

RKY designed and drafted the manuscript. STZ carried out literature search and drafted the manuscript. TIT drafted and revised the manuscript. All authors read and approved the final manuscript.

\section{Competing interests}

The authors declare that they have no competing interests.

Consent for publication

Not applicable.

Ethics approval and consent to participate Not applicable.

\section{Author details}

${ }^{1}$ Department of Intensive Care Medicine, Tampere University Hospital, University of Tampere, 10 Bio katu, Tampere 33014, Finland. ${ }^{2}$ Department of Critical Care Medicine, University of Pittsburgh Medical School, 3550 Terrace Street, Pittsburgh, PA 15261, USA. ${ }^{3}$ Department of Emergencies and Critical Care, Oslo University Hospital, Oslo, Norway. ${ }^{4}$ Department of

Gastroenterology, Beijing Friendship Hospital, Capital Medical University, 95 Yong An Road, Beijing 100050, China. ${ }^{5}$ Institute of Clinical Medicine,

University of Oslo, Oslo, Norway. 


\section{Received: 26 August 2016 Accepted: 18 November 2016} Published online: 03 December 2016

\section{References}

1. Fink MP. Ethyl pyruvate. Curr Opin Anaesthesiol. 2008;21:160-7.

2. Kao K, Fink MP. The biochemical basis for the anti-inflammatory and cytoprotective actions of ethyl pyruvate and related compounds. Biochem Pharmacol. 2010;80:151-9.

3. Yang Z, Meng X, Xu P. Central role of neutrophil in the pathogenesis of severe acute pancreatitis. J Cell Mol Med. 2015;19:2513-20.

4. Luan ZG, Ma XC, Zhang H, Zhang C, Guo RX. Protective effect of ethyl pyruvate on pancreas injury in rats with severe acute pancreatitis. J Surg Res. 2013;181:76-84.

5. Hegazi R, Raina A, Graham T, Rolniak S, Centa P, Kandil H, O'keefe SJ. Early jejunal feeding initiation and clinical outcomes in patients with severe acute pancreatitis. J Parenter Enteral Nutr. 2011;35:91-6.

6. Yang R, Uchiyama T, Alber SM, Han X, Watkins SK, Delude RL, Fink MP. Ethyl pyruvate ameliorates distant organ injury in a murine model of acute necrotizing pancreatitis. Crit Care Med. 2004;32:1453-9.

7. Tadao M, Yuji O. Role of free radicals in the development of severe acute pancreatitis. Nihon Rinsho. 2004;62:2015-20.

8. Akbarshahi $H$, Rosendahl AH, Westergren-Thorsson G, Andersson R. Acute lung injury in acute pancreatitis-awaiting the big leap. Respir Med. 2012;106:1199-210.

9. Yuan Z, Meyerholz DK, Twait EC, Kempuraj D, Williard DE, Samuel I. Systemic inflammation with multiorgan dysfunction is the cause of death in murine ligation-induced acute pancreatitis. J Gastrointest Surg. 2011;15:1670-8.

10. Yang Z, Ling Y, Yin T, Tao J, Xiong J, Wu H, Wang C. Delayed ethyl pyruvate therapy attenuates experimental severe acute pancreatitis via reduced serum high mobility group box 1 levels in rats. World J Gastroenterol. 2008;14:4546-50.

11. Cheng B, Liu C, Li W, Fan W, Zhong N, Zhang Y, Jia X, Zhang SZ. Ethyl pyruvate improves survival and ameliorates distant organ injury in rats with severe acute pancreatitis. Pancreas. 2007;35:256-61.

12. Yang R, Shaufl AL, Killeen MK, Fink MP. Ethyl pyruvate ameliorates liver injury secondary to severe acute pancreatitis. JSR. 2009;153:302-9.

13. Luan Z, Zhang H, Ma X, Zhang C, Guo R. Therapeutic treatment with ethyl pyruvate attenuates the severity of liver injury in rats with severe acute pancreatitis. Pancreas. 2012;41:729-37.

14. Shen X, Li WQ. High-mobility group box 1 protein and its role in severe acute pancreatitis. World J Gastroenterol. 2015;1:1424-35.

15. Tsung A, Sahai R, Tanaka H, Nakao A, Fink MP, Lotze MT, Yang H, Li J, Tracey KJ, Geller DA, Billiar TR. The nuclear factor HMGB1 mediates hepatic injury after murine liver ischemia-reperfusion. JEM. 2005;201:1135-43.

16. Sappington PL, Yang R, Yang H, Tracey KJ, Deluder RL, Fink MP. HMGB1 B box increases the permeability of Caco-2 enterocytic monolayers and impairs intestinal barrier function in mice. Gastroenterology. 2002;123:790-802.

17. Yang R, Zhang S, Cotoia A, Oksala N, Zhu S, Tenhunen J. High mobility group B1 impairs hepatocyte regeneration in acetaminophen hepatotoxicity. BMC Gastroenterol. 2012;12:45

18. Antoine DJ, Williams DP, Kipar A, Laverty H, Park BK. Diet restriction inhibits apoptosis and HMGB1 oxidation and promotes inflammatory cell recruitment during acetaminophen hepatotoxicity. Mol Med. 2010;16:479-90.

19. Lau A, Wang S, Liu W, Haig A, Zhang Z, Jevnikar AM. Glycyrrhizic acid ameliorates HMGB1-mediated cell death and inflammation after renal ischemia reperfusion injury. Am J Nephrol. 2014;40:84-95.

20. Hu Y, Pai MH, Yeh CL, Hou YC, Yeh SL. Glutamine administration ameliorates sepsis-induced kidney injury by downregulating the highmobility group box protein-1-mediated pathway in mice. Am J Physiol Renal Physiol. 2012;302:F150-8.

21. Sawa H, Ueda T, Takeyama Y, Yasuda T, Shinzeki M, Nakajima T, Kuroda Y. Blokade of high mobility group box-1 protein attenuates experimental severe acute pancreatitis. World J Gastroenterol. 2006;12:7666-70

22. Kao RL, Xu X, Xenocostas A, Parry N, Mele T, Martin CM, Rui T. Induction of acute lung inflammation in mice with hemorrhagic shock and reperfusion: role of HMGB1. J Inflamm (Lond). 2014;11:30-7.

23. Tsai BM, Lahm T, Morrell El, Crisostomo PR, Poynter J, Wang M, Meldrum DR. Ethyl pyruvate inhibits hypoxic pulmonary vasoconstriction and attenuates pulmonary artery cytokine expressions. J Surg Res. 2008;145:130-4

24. Luan Z, Zhang X, Yin X, Ma X, Zhang H, Zhang C, Guo R. Downregulation of HMGB1 protects against the development of acute lung injury after severe acute pancreatitis. Immunobiology. 2013;218:1261-70.
25. Yang R, Zou X, Tenhunen J, Zhu S, Kajander H, Koskinen M, Tonesseen TI. Neutralization of HMGB1 is associated with bacterial translocation during acetaminophen hepatotoxicity. BMC Gastroenterol. 2014;14:66.

26. Fink MP. Leaky gut hypothesis: a historical perspective. Crit Care Med. 1990;18: 579-80.

27. Li Q, Wang C, Tang C, He Q, Li N, Li J. Bacteraemia in patients with acute pancreatitis as revealed by $16 \mathrm{~s}$ ribosomal RNA gene-based technique. CCM 2013;41:1938-50.

28. Fritz S, Hackert T, Hartwig W, Rossmanith F, Strobel O, Schneider L, Will-Schweiger K, Kommerell M, Buchler MW, Werner J. Bacterial translocation and infected pancreatic necrosis in acute necrotizing pancreatitis derives from small bowel rather than from colon. Am J Surg. 2010;200:111-7.

29. Capurso G, Zerboni G, Signoretti M, Valente R, Stigliano S, Piciuchi M, Delle FG. Role of the gut barrier in acute pancreatitis. J Clin Gastroenterol. 2012:46:S46-51.

30. Guo Z, Wang P, Zhu Y, Huang Z, Tang C. The crosstalk between gut inflammation and gastrointestinal disorders during acute pancreatitis. Curr Pharm Des. 2014;20:1051-62.

31. Wang XD, Andersson R, Stoltesz V, Leveau P, Ihse I. Gut origin sepsis, macrophage function, and oxygen extraction associated with acute pancreatitis in the rat. World J Surg. 1996;20:299-308.

32. Chen H, Li F, Jia J, Diao Y, Li Z, Sun J. Effect of traditional Chinese medicine on intestinal mucosal permeability in early phase of severe acute pancreatitis. Chin Med J (Engl). 2010;123:1537-42.

33. Runkel N. Bacterial translocation in acute pancreatitis. Dig Surg. 1996;13:269-72

34. Fanous M, Phillips AJ, Windsor JA. Mesenteric lymph: The bridge to future management of critical illness. JOP J Pancreas. 2007;8:374-99.

35. Ramadori G, Moroconi F, Malik I, Dudas J. Physiology and pathophysiology of liver inflammation, damage and repair. J physiol Pharmacol. 2008:59:107-17.

36. Gloor B, Blinman TA, Rigberg DA, Todd KE, Lane JS, Hines OJ, et al. Kupffer cell blockade reduces hepatic and systemic cytokine levels and lung injury in hemorrhagic pancreatitis in rats. Pancreas. 2000;21:414-20.

37. Yang R, Han X, Delude RL, Fink MP. Ethyl pyruvate ameliorates acute alcoholic-induced liver injury and inflammation in mice. J Lab and Clinic Med. 2003;142:322-31.

38. Yang R, Uchiyama T, Watkins SK, Han X, Fink MP. Ethyl pyruvate reduces liver injury in a murine model of extrahepatic cholestasis. Shock. 2004;22:369-75.

39. Yang R, Zhang S, Kajander H, Zhu S, Koskinen ML, Tenhunen J. Ringer's lactate improves liver recovery in a murine model of acetaminophen toxicity. BMC Gastroenterol. 2011;11:125.

40. Stine JG, Chalasani NP. Drug hepatotoxicity: environmental factors. Clin Liver Dis. 2017;21:103-13.

41. Ole RA, Ziokowski W, Flis DJ, Fedeli D, Fiorini D, Wierzba TH, Gabbianelli R. The effect of ethyl pyruvate supplement on rat fatty liver induced by a high-fat diet. J Nutr Sci Vitaminol (Tokyo). 2013;59:232-7.

42. Shen M, Lu J, Dai W, et al. Ethyl pyruvate ameliorates hepatic ischemiareperfusion injury by inhibiting intrinsic pathway of apoptosis and autophagy. Mediators Inflamm. 2013;2013:461536.

43. Yang R, Zou X, Koskinen ML, Tenhunen J. Ethyl pyruvate reduces liver injury at early phase but impairs regeneration at late phase in acetaminophen overdose. Crit Care. 2012;16:R9.

44. Shen M, Lu J, Cheng P, et al. Ethyl pyruvate pretreatment attenuates concanavalin A-induced autoimmune hepatitis in mice. PLoS One. 2014:9:e87977.

45. Wang LK, Wang LW, Li X, Han XQ, Gong ZJ. Ethyl pyruvate prevents inflammatory factors release and decreases intestinal permeability in rats with D-galactosamine-induced acute liver failure. Hepatobiliary Pancreat Dis Int. 2013;12:180-8.

46. Wang LW, Wang LK, Chen H, Fan C, Li X, He CM, Gong ZJ. Ethyl pyruvate protects against experimental acute-on-chronic liver failure in rats. World Gastroenterol. 2012;18:5709-18.

47. Akkoc H, Kelle I, Tunik S, Bahceci S, Sencar L, Ayaz E, Nergiz Y, Erdinc L, Erdinc M. Protective effect of ethyl pyruvate on liver injury in diabetic strptozotocin-induced rats. Acta Gastroenterol Belg. 2012;75:336-41.

48. Andersson B, Ansari D, Andersson E, Persson S, Andersson R. Fatal acute pancreatitis occurring outside of the hospital: clinical and social characteristics. World J Surg. 2010;34:2286-91.

49. Pastor CM, Matthay MA, Frossard JL. Pancreatitis-associated acute lung injury: new insights. Chest. 2003:124:2341-51.

50. Shields CJ, Winter DC, Redmond HP. Lung injury in acute pancreatitis: mechanism, prevention, and the therapy. Curr Opin Crit Care. 2002:8:158-63. 
51. Zhao X, Andersson R, Wang X, Dib M. Acute pancreatitis-associated lung injury: pathophysiological mechanisms and potential future therapies. Scand J Gastroenterol. 2002;37:1351-8.

52. Matone J, Moretti Al, Apodaca-Torrez FR, Goldenberg A. Ethyl pyruvate reduces lung injury matrix metalloproteinases and cytokines and improves survival in experimental model of severe acute pancreatitis. Acta Cir Bras. 2013;28:559-67.

53. Luan ZG, Zhang J, Yin XH, Ma XC, Guo RX. Ethyl pyruvate significantly inhibits tumor necrosis factor-a interleukin-1 and high mobility group box 1 releasing and attenuates sodium taurocholate-induced severe acute pancreatitis associated acute lung injury. Clin Exp Immunol. 2013;172:417-26.

54. Relja B, Omid N, Schaible A, Perl M, Meier S, Oppermann E, Lehnert M, Marz I. Pre-or post-treatment with ethanol and ethyl pyruvate results in distinct anti-inflammatory response of human lung epithelial cells triggered by interleukin-6. Mol Med Rep. 2015;12:2991-8.

55. Relja B, Omid N, Wagner N, Mors K, Werner I, Perl M, Marzi I. Ethanol, ethyl and sodium pyruvate decrease the inflammatory response of human lung epithelial cells via Akt and NF-kB in vitro but have low impact on hepatocellular cells. Int J Mol Med. 2016;37:517-25.

56. Kung CW, Lee YM, Cheng PY, Peng YJ, Yen MH. Ethyl pyruvate reduces acute lung injury via regulation of iNOS and $\mathrm{HO}-1$ expression in endotoxemic rats. J Surg Res. 2011;167:e323-31.

57. Shang GH, Lin DJ, Xiao W, Jia CQ, Li Y, Wang AH, Dong L. Ethyl pyruvate reduces mortality in an endotoxin-induced severe acute lung injury mouse model. Respir Res. 2009;10:91

58. Entezari M, Javdan M, Antoine DJ, et al. Inhibition of extracellular HMGB1 attenuates hyperoxia-induced inflammatory acute lung injury. Redox Biol. 2014:2:314-22

59. Tian XX, Wu CX, Sun H, Gong JP, Liu Q, Guo H. Ethyl pyruvate inhibited HMGB1 expression induced by LPS in macrophages. Xi Bao Yu Fen Zi Mian Yi Xue Za Zhi. 2011;27:1304-7.

60. Jang HJ, Kim YM, Tsoyi K, Park EJ, Lee YS, Kim HJ, Lee JH, Joe Y, Chung HT, Chang KC. Ethyl pyruvate induces heme oxygenase-1 through p38 mitogen-activated protein kinase activation by depletion of glutathione in Raw 264.7 cells and improves survival in septic animals. Antioxid Redox Signal. 2012;17:878-89.

61. Ulloa L, Ochani M, Yang H, Tanovic M, Halperin D, Yang R, Czura CJ, Fink MP, Tracey KJ. Ethyl pyruvate prevents lethality in mice with established lethal sepsis and systemic inflammation. Proc Natl Acad Sci. 2002;99:12351-6.

62. Gazzar ME. HMGB1 modulates inflammatory responses in LPS-activated macrophages. Inflamm Res. 2007;56:162-7.

63. Yang $\mathrm{H}$, Hreggvidsdottir $\mathrm{HS}$, Palmblad $\mathrm{K}$, et al. A critical cysteine is required for HMGB1 binding to toll-like receptor 4 and activation of macrophage cytokine release. Proc Natl Acad Sci U S A. 2010;26:11942-7.

64. Kang H, Mao Z, Zhao Y, Yin T, Song Q, Pan L, Hu X, Hu J, Zhou F. Ethyl pyruvate protects against sepsis by regulating energy metabolism. Ther Clin Risk Manag. 2016;12:287-94.

65. Jiang Z, Li X, Lin Z, Chen J, Guan X, Chen M. Ethyl pyruvate reduces hepatic mitochondrial swelling and dysfunction in a rat model of sepsis. Int J Clin Exp Pathol. 2015;8:7774-85

66. Zheng YJ, Xu WP, Ding G, Gao YH, Wang HR, Pan SM. Expression of HMGB1 in septic serum induces vascular endothelial hyperpermeability. Mol Med Rep. 2016;13:513-21.

67. Wang G, Liu K, Li Y, Yi W, Yang Y, Zhao D, Fan C, Yang H, Geng T, Xing J, Zhang Y, Tan S, Yi D. Endoplasmic reticulum stress mediates the anti-inflammatory effect of ethyl pyruvate in endothelial cells. PLoS One. 2014;9:e113983.

68. Miyaji T, Hu X, Yuen PS, Muramatsu Y, Lyer S, Hewitt SM, Star RA. Ethyl pyruvate decreases sepsis-induced acute renal failure and multiple organ damage in aged mice. Kidney Int. 2003;64:1620-31.

69. Ju KD, Shin EK, Cho EJ, Yoon HB, Kim H, Yang J, Hwang YH, Ahn C, Oh KH. Ethyl pyruvate ameliorates albuminuria and glomerular injury in the animal model of diabetic nephropathy. Am J Physiol Renal Physiol. 2012;302:F606-13.

70. Kelle I, Akkoc H, Tunik S, Nergiz Y, Erdinc M, Erdinc L. Protective effects of ethyl pyruvate in cisplatin-induced nephrotoxicity. Biotechnol Biotechnol Equip. 2014;28:674-80.

71. Yu Y, Liu M, Yu P, Liu G, Liu Y, Su Y, Jiang H, Chen R. Ethyl pyruvate attenuated coxackievirus B3-induced acute viral myocarditis by suppressing of HMGB1/RAGE/NF-kB pathway. Springerplus. 2016:5:215.

72. Lin Y, Chen L, Li W, Fang J. Role of high-mobility group box 1 in myocardial ischemia/reperfusion injury and the effect of ethyl pyruvate. Exp Ther Med. 2015:9:1537-41
73. Guo J, Zhang J, Luo X, Luo W, Lin C, Zhang K, Ji Y. Effects of ethyl pyruvate on cardiac function recovery and apoptosis reduction after global cold ischemia and reperfusion. Exp Ther Med. 2014;7:1197-202.

74. Jang IS, Park MY, Shin IW, Sohn JT, Lee HK, Chung YK. Ethyl pyruvate has anti-inflammatory and delayed myocardial protective effects after regional ischemia/reperfusion injury. Yonsei Med J. 2010;51:838-44.

75. Woo YJ, Taylor MD, Cohen JE, Jayasankar V, Bish LT, Burdick J, Pirolli TJ, Berry MF, Hsu V, Grand T. Ethyl pyruvate preserves cardiac function and attenuates oxidative injury after prolonged myocardial ischemia. J Thorac Cardiovasc Surg. 2004;127:1262-9.

76. Moro N, Sutton RL. Beneficial effects of sodium or ethyl pyruvate after traumatic brain injury in the rat. Exp Neurol. 2010;225:391-401.

77. Su X, Wang H, Zhao J, Pan H, Mao L. Beneficial effects of ethyl pyruvate through inhibiting high-mobility group box 1 expression and TLR4/NFkB pathway after traumatic brain injury in the rat. Mediators Inflamm. 2011; 2011:807142.

78. Shi H, Wang HL, Pu HJ, Shi YJ, Zhang J, Zhang WT, Wang GH, Hu XM, Leak RK, Chen J, Gao YQ. Ethyl pyruvate protects against blood-brain barrier damage and improves long-term neurological outcomes in a rat model of traumatic brain injury. CNS Neurosci Ther. 2015;21:374-84.

79. Moro N, Ghavim SS, Harris NG, Hovda DA, Sutton RL. Pyruvate treatment attenuates cerebral metabolic depression and neuronal loss after traumatic experimental brain injury. Brain Res. 2016;1642:270-7.

80. Su X, Wang H, Zhu L, Zhao J, Pan H, Ji X. Ethyl pyruvate ameliorates intracerebral hemorrhage-induced brain injury through anti-cell death and anti-inflammatory mechanisms. Neuroscience. 2013;245:99-108.

81. Li D, Lei C, Zhang S, Zhang S, Liu M, Wu B. Blockade of high mobility group box-1 signaling via the receptor for advanced glycation end-products ameliorates inflammatory damage after acute intracerebral hemorrhage. Neurosci Lett. 2015;609:109-19.

82. Fang $\mathrm{R}$, Zheng $\mathrm{X}$, Zhang $\mathrm{M}$. Ethyl pyruvate alleviates early brain injury following subarachnoid hemorrhage in rats. Acta Neurochir (Wien). 2016; 158:1069-76.

83. Yu YM, Kim JB, Lee KW, Kim SY, Han PL, Lee JK. Inhibition of the cerebral ischemic injury by ethyl pyruvate with a wide therapeutic window. Stroke. 2005;36:2238-43.

84. Rong Z, Pan R, Chang L, Lee W. Combination treatment with ethyl pyruvate and IGF-I exerts neuroprotective effects against brain injury in a rat model of neonatal hypoxic-ischemic encephalopathy. Int J Mol Med. 2015;36:195-203.

85. Guo X, Guo R, Luo X, Zhou L. Ethyl pyruvate ameliorates experimental colitis in mice by inhibiting the HMGB1-Th17 and Th1/Tc1 responses. Int Immunopharmacol. 2015;29:454-61.

86. Algien F, Rodriguez-Nogales A, Garrido-Mesa J, Camuesco D, Vezza T, GarridoMesa N, Utrilla P, Rodriguez-Cabezas ME, Pischel I, Galvez J. Intestinal antiinflammatory activity of calcium pyruvate in the TNBS model of rat colitis: comparison with ethyl pyruvate. Biochem Pharmacol. 2016;103:53-63.

87. Liang X, Chavez AR, Schapiro NE, Loughran P, Thorne SH, Amoscato AA, Zeh HJ, Beer-Stolz D, Lotze MT, de Vera ME. Ethyl pyruvate administration Inhibits hepatic tumor growth. J Leukoc Biol. 2009;86:599-607.

88. Muller AJ, Duhadaway JB, Jaller D, Curtis P, Metz R, Prendergast GC. Immunotherapeutic suppression of indoleamine 2, 3-dioxygenase and tumor growth with ethyl pyruvate. Cancer Res. 2010;70:1845-53.

89. Park SY, Yi EY, Jung M, Lee YM, Kim YJ. Ethyl pyruvate, an anti- inflammatory agent, inhibits tumor angiogenesis through inhibition of NF-kB signaling pathway. Cancer Lett. 2011;303:150-4.

90. Zhang J, Zhu JS, Zhou Z, Chen WX, Chen NW. Inhibition effects of ethyl pyruvate administration on human gastric cancer growth via regulation of HMGB1-Rage and Akt pathways in vitro and in vivo. Oncol Rep. 2012;27:1511-9.

91. Li ML, Wang XF, Tan ZJ, et al. Ethyl pyruvate administration suppresses growth and invasion of gallbladder cancer cells via downregulation of HMGB1-RAGE axis. Int J Immunopathol Pharmacol. 2012;25:955-65.

92. Yan HX, Wu HP, Zhang HL, Ashton C, Tong C, Wu H, Qian QJ, Wang HY, Ying QL. P53 promotes inflammation-associated hepatocarcinogenesis by Inducing HMGB1 release. J Hepatol. 2013;59:762-8.

93. Cheng P, Dai W, Wang F, et al. Ethyl pyruvate inhibits proliferation and induces apoptosis of hepatocellular carcinoma via regulation of HMGB1RAGE and Akt pathways. Biochem Biophys Res Commun. 2014;443:1162-8.

94. Baunacke M, Horn LC, Trettner S, Engel KM, Hemdan NY, Wiechmann V, Stolzenburg JU, Bigl M, Birkenmeier G. Exploring glyoxalase 1 expression in prostate cancer tissues: targeting the enzyme by ethyl pyruvate defangs some malignancy-associated properties. Prostate. 2014;74:48-60. 
95. Dave SH, Tilstra JS, Matsuoka K, Li F, DeMarco RA, Beer-Stolz D, Sepulveda AR, Fink MP, Lotze MT, Plevy SE. Ethyl pyruvate decreases HMGB1 release and ameliorates murine colitis. J Leukoc Biol. 2009;86:633-43.

96. Mizutani A, Maeda N, Toku S, Higa-Nakamine S, Isohama Y, Sunakawa H, Suqahara K, Yamamoto H. Interaction of ethyl pyruvate in vitro with NF-kB subunits, Rel A and p50. Eur J Pharmacol. 2011;605:151-6.

97. Shin JH, Kim ID, Kim SW, Lee HK, Jin Y, Park JH, Kim TK, Suh CK, Kwak J, Lee $\mathrm{KH}$, Han PL, Lee JK. Ethyl pyruvate inhibits HMGB1 phosphorylation and release by chelating calcium. Mol Med. 2015;20:649-57.

98. Kim SW, Lee HK, Kim HJ, Yoon SH, Lee JK. Neuroprotective effect of ethyl pyruvate against $\mathrm{Zn}(2+)$ toxicity via NAD replenishment and direct $\mathrm{Zn}$ aa2 +) chelation. Neuropharmacology. 2016;105:411-9.

Submit your next manuscript to BioMed Central and we will help you at every step:

- We accept pre-submission inquiries

- Our selector tool helps you to find the most relevant journal

- We provide round the clock customer support

- Convenient online submission

- Thorough peer review

- Inclusion in PubMed and all major indexing services

- Maximum visibility for your research

Submit your manuscript at www.biomedcentral.com/submit
Biomed Central 